\title{
CCL2 Released from Neuronal Synaptic Vesicles in the Spinal Cord Is a Major Mediator of Local Inflammation and Pain after Peripheral Nerve Injury
}

\author{
Juliette Van Steenwinckel, ${ }^{1}$ Annabelle Reaux-Le Goazigo, ${ }^{1}$ Blandine Pommier, ${ }^{1}$ Annie Mauborgne, ${ }^{1}$ \\ Marc-André Dansereau, ${ }^{2}$ Patrick Kitabgi, ${ }^{1}$ Philippe Sarret, ${ }^{2}$ Michel Pohl, ${ }^{1}$ and Stéphane Mélik Parsadaniantz ${ }^{1}$ \\ 'Pain Group, Centre de Recherche de l'Institut du Cerveau et de la Moelle Epinière, Université Pierre et Marie Curie, Inserm Unité Mixte de Recherche en \\ Santé 975, Centre National de la Recherche Scientifique, Unité Mixte de Recherche 7225, 75013 Paris, France, and ${ }^{2}$ Department of Physiology and \\ Biophysics, Faculty of Medicine and Health Sciences, University of Sherbrooke, Sherbrooke, Quebec J1H 5N4, Canada
}

CCL2 chemokine and its receptor CCR2 may contribute to neuropathic pain development. We tested the hypothesis that injury to peripheral nerves triggers CCL2 release from afferents in the dorsal horn spinal cord (DHSC), leading to pronociceptive effects, involving the production of proinflammatory factors, in particular. Consistent with the release of CCL2 from primary afferents, electron microscopy showed the CCL2 immunoreactivity in glomerular boutons and secretory vesicles in the DHSC of naive rats. Through the ex vivo superfusion of DHSC slices, we demonstrated that the rate of CCL2 secretion was much lower in neonatal capsaicin-treated rats than in controls. Thus, much of the CCL2 released in the DHSC originates from nociceptive fibers bearing TRPV1 (transient receptor potential vanilloid 1). In contrast, high levels of CCL2 released from the DHSC were observed in neuropathic pain animal model induced by chronic constriction of the sciatic nerve (SN-CCI). The upregulated expression of proinflammatory markers and extracellular signal-regulated kinase (ERK) 1/2 pathway activation (ERK1/2 phosphorylation) in the DHSC of SN-CCI animals were reversed by intrathecal administration of the CCR2 antagonist INCB3344 ( $N$-[2-[[(3S,4S)-1-E4-(1,3-benzodioxol-5-yl)-4-hydroxycyclohexyl]-4-ethoxy-3-pyrrolidinyl]amino]2-oxoethyl]-3-(trifluoromethyl)benzamide). These pathological pain-associated changes in the DHSC were mimicked by the intrathecal injection of exogenous CCL2 in naive rats and were prevented by the administration of INCB3344 or ERK inhibitor (PD98059). Finally, mechanical allodynia, which was fully developed 2 weeks after SN-CCI in rats, was attenuated by the intrathecal injection of INCB3344. Our data demonstrate that CCL2 has the typical characteristics of a neuronal mediator involved in nociceptive signal processing and that antagonists of its receptor are promising agents from treating neuropathic pain.

\section{Introduction}

Chronic neuropathic pain is a major public health issue, particularly because it is often difficult to treat effectively with conventional drugs. Peripheral nerve injury has been shown to trigger the secretion of proinflammatory factors, contributing to the genesis and maintenance of neuropathic pain (Scholz and Woolf, 2007; Milligan and Watkins, 2009). These factors include the chemokine CCL2 and its cognate receptor CCR2,

\footnotetext{
Received Nov. 12, 2010; revised Feb. 5, 2011; accepted Feb. 21, 2011.

Author contributions: J.V.S., A.R.-L.G., M.P., and S.M.P. designed research; J.V.S., A.R.-L.G., B.P., A.M., M.A.D., M.P., and S.M.P. performed research; J.V.S., A.R.-L.G., P.K., P.S., M.P., and S.M.P. analyzed data; J.V.S., A.R.-L.G., P.K., P.S., M.P., and S.M.P. wrote the paper.

This study was supported by Agence Nationale pour la Recherche Grant R06282DS, Université Pierre and Marie Curie (Paris VI), Institut National de la Santé et de la Recherche Médicale, Association Française contre les Myopathies, and the Canadian Institutes of Health Research. M.A.D. holds the Sir Frederick Banting and Dr. Charles Best Canada Graduate Scholarships, and P.S. is a Canadian Institutes of Health Research new investigator. We thank Global Pfizer for providing us with the CCR2-specific antagonist (INCB3344). We thank Dominique Langui from the local imaging platform (PICPS) for advice and help with image analysis.

Correspondence should be addressed to Stéphane Mélik Parsadaniantz, Centre de Recherche de l'Institut du Cerveau et de la Moelle Epinière, Université Pierre et Marie Curie, Inserm, Unité Mixte de Recherche en Santé 975, Centre National de la Recherche Scientifique, Unité Mixte de Recherche 7225, Équipe Douleurs, Faculté de Médecine Pitié Salpêtrière, 91 boulevard de l'Hôpital, 75013 Paris, France. E-mail: stephane.melik-parsadaniantz@inserm.fr. DOI:10.1523/JNEUROSCI.5986-10.2011

Copyright $\odot 2011$ the authors $\quad 0270-6474 / 11 / 315865-11 \$ 15.00 / 0$
}

which seem to play an important role in regulating nociceptive responses and in the establishment of chronic neuropathic pain (for review, see White et al., 2007; Gosselin et al., 2008; White and Miller, 2010). Thus, the SN-CCI model is markedly attenuated in CCR2 knock-out mice (Abbadie et al., 2003). Moreover, intrathecal injection of CCL2 in rats induces prolonged hyperalgesia and allodynia (Tanaka et al., 2004; Dansereau et al., 2008), these effects being reversed by a CCR2 antagonist (Dansereau et al., 2008). In vitro, CCL2 strongly inhibits GABAergic transmission in primary spinal neurons (Gosselin et al., 2005) and sensitizes nociceptors by activating capsaicin transient receptor potential vanilloid 1 (TRPV1) (Jung et al., 2008). The application of CCL2 to the cell bodies of primary sensory neurons from formerly compressed dorsal root ganglia (DRG) also elicits robust excitatory effects (White et al., 2005).

There are several lines of evidence suggesting that CCL2 and its receptor CCR2 are expressed in both neurons and glial cells in the dorsal horn of the spinal cord (DHSC) of healthy rats and animal models of neuropathic pain (White et al., 2005; Dansereau et al., 2008; Thacker et al., 2009). Furthermore, after KCL depolarization, CCL2 is secreted in a calcium-dependent manner 
from DRG and DHSC explants prepared from naive rats, suggesting its release from neuronal cells (Dansereau et al., 2008). These data are consistent with nerve injury triggering the release of CCL2 from primary afferent neurons in the DHSC, in which it may have pronociceptive effects, including changes in the production of proinflammatory factors.

We tested this hypothesis by examining the subcellular distribution of CCL2 in DHSC from naive rat, by electron microscopy. We performed ex vivo studies, comparing CCL2 basal and tissue depolarization $\left(\mathrm{K}^{+}\right)$-evoked secretion rates from DHSC slices in naive rats, $\mathrm{SN}$-CCI rats, and animals in which many of the primary sensory neurons were destroyed by neonatal treatment with capsaicin (Pohl et al., 1990). We also assessed the role of CCL2 in neuropathic pain-associated spinal cord plasticity, by evaluating the extent to which a selective CCR2 antagonist modulates the expression of various proinflammatory factors in the DHSC of $\mathrm{SN}-\mathrm{CCI}$ rats and accumulation of the phosphorylated (p) (active) form of extracellular signal-regulated kinase (ERK) $1 / 2$, which is known to be involved in pain signaling (Zhuang et al., 2005). Finally, we evaluated the efficacy of a CCR2 antagonist for attenuating established mechanical allodynia in the SN-CCI model.

We found that CCL2 had many of the characteristics typical of neuronal mediators involved in pain signaling and showed that the targeting of spinal CCR2 with selective antagonists was a potentially effective intervention for chronic neuropathic pain.

\section{Materials and Methods}

\section{Animals}

Animals (adult male Sprague Dawley rats weighing 200-220 or 250-350 g; Centre d'Elevage Janvier, Le Genest-St Isle, France) were maintained under controlled conditions $\left(22 \pm 1^{\circ} \mathrm{C}, 60 \pm 10 \%\right.$ relative humidity, $12 \mathrm{~h}$ light/dark cycle, food and water ad libitum). All experiments were performed in accordance with institutional guidelines complying with national and international laws and guidelines for the use of animals in neuroscience research (European Communities Council Directive number 87848, October 1987, Ministère de l'Agriculture et de la Forêt, Service Vétérinaire de la Santé et de la Protection Animale).

Neonatal capsaicin treatment. Male Sprague Dawley rats were treated on the second postnatal day with capsaicin (Sigma; $50 \mathrm{mg} / \mathrm{kg}$, s.c.) or with vehicle ( $20 \mu \mathrm{l}$ of $10 \%$ ethanol and $10 \%$ Tween 20 in saline) as described previously (Pohl et al., 1990). They were killed 3 months later, and their spinal cords were dissected, as described below.

Chronic constriction injury to the sciatic nerve. Rats were anesthetized with volatile isoflurane (Baxter), and the left sciatic nerve was exposed. Under a dissection microscope, four chromic catgut (5-0) ligations were tied loosely at a spacing of $1 \mathrm{~mm}$, proximally to the sciatic trifurcation (Bennett and Xie, 1988). Finally, the skin was sewed up with silk sutures (4-0). In sham-operated animals, the same procedure was performed but without ligation of the nerve.

Intrathecal injections of CCL2, CCR2 antagonist (INCB3344), or p-ERK1/2 inhibitor (PD98059) and tissue collection. The injection protocol and the doses of CCL2, INCB3344 (N-[2-[[(3S,4S)-1-E4-(1,3-benzodioxol-5-yl)4-hydroxycyclohexyl]-4-ethoxy-3-pyrrolidinyl] amino]-2-oxoethyl]-3(trifluoromethyl)benzamide), or PD98059 [2-(2-amino-3-methyoxyphenyl)-4 H-1-benzopyran-4-one] used were the same for all experiments. Rats were placed under isoflurane anesthesia, and 1 $\mu \mathrm{g}$ of CCL2 (Peprotech), $14.38 \mu \mathrm{g}$ (1 mM) of INCB3344 (Global Pfizer) (Brodmerkel et al., 2005), $10 \mu \mathrm{g}$ of PD98059 (Cell Signaling Technology), or vehicle (saline alone or saline $+1.15 \%$ DMSO or saline $+3 \%$ DMSO) were injected into the rats, via the intrathecal route, between the L5 and L6 vertebrae, in a total volume of $25 \mu \mathrm{l}$.

For analysis of the effects of CCL2 on mRNAs encoding proinflammatory mediators or ERK1/2 phosphorylation in the spinal cord, animals received a single intrathecal injection of INCB3344 or vehicle $1 \mathrm{~h}$ before the intrathecal injection of CCL 2 or saline. Tissues were collected $1 \mathrm{~h}$ later for protein phosphorylation analysis and $2 \mathrm{~h}$ later for analyses of mRNA levels.

For the experiments with MEK1 (MAP kinase kinase 1) inhibitor, animals received a single intrathecal injection of PD98059 or vehicle, 30 min before intrathecal injection of CCL2 or saline. Behavioral test was performed $4 \mathrm{~h}$ after saline/CCL2 injection. Animals were then killed and tissues were collected.

For the time course study of CCL 2 mRNA levels, tissues were collected $1,2,3,7,15,21,30$, and $60 \mathrm{~d}$ after the SN-CCI procedure. For analysis of the effects of INCB3344 on mRNAs encoding proinflammatory mediators or on ERK1/2 phosphorylation in the spinal cord of SN-CCI rats, animals received three intrathecal injections of INCB3344 or vehicle, at $24 \mathrm{~h}$ intervals, between 15 and $17 \mathrm{~d}$ after injury. Tissues were collected $5 \mathrm{~h}$ after the last injection.

For reverse transcription (RT)-quantitative PCR (qPCR) and Western blot studies, tissue were collected from deeply anesthetized animals (pentobarbital at $50 \mathrm{mg} / \mathrm{kg}$, i.p.; Sanofi) perfused transcardially with $50 \mathrm{ml}$ of $0.9 \% \mathrm{NaCl}$. The ipsilateral L4-L6 DRG and DHSC were rapidly dissected at $0-4^{\circ} \mathrm{C}$, then immediately frozen in liquid nitrogen, and stored at $-80^{\circ} \mathrm{C}$ until use. For immunohistochemical detection of phospoERK1/2, tissues were processed as described below.

\section{Immunohistochemical studies}

Tissue preparation. Animals were deeply anesthetized with sodium pentobarbital, (50 mg/kg, i.p.; Sanofi) and perfused intracardially with 100 $\mathrm{ml}$ of saline $(0.9 \% \mathrm{NaCl})$, followed by $500 \mathrm{ml}$ of $4 \%$ paraformaldehyde in $0.1 \mathrm{M}$ PBS supplemented with $0.8 \%$ picric acid. For electron microscopy, the $4 \%$ paraformaldehyde solution was supplemented with $1 \%$ picric acid for preembedding immunohistochemistry or with $1 \%$ picric acid and $0.5 \%$ glutaraldehyde for postembedding immunohistochemistry. Lumbar enlargements of the spinal cord were postfixed overnight and cut into $40 \mu \mathrm{m}$ sections with a vibratome (Leica VT 1000S; Leica Microsystems).

Immunofluorescence labeling. Spinal cord sections were incubated with $3 \%$ normal goat serum (NGS) and $0.1 \%$ Triton X-100 in $0.1 \mathrm{~m} \mathrm{PBS} \mathrm{for}$ $2 \mathrm{~h}$. The sections were then incubated overnight at $4^{\circ} \mathrm{C}$ with rabbit polyclonal anti-p-p44/42 mitogen-activated protein kinase (MAPK) (p$\mathrm{p} 44 / 42$ MAPK or p-ERK1/2) or rabbit polyclonal anti-p-AKT or rabbit polyclonal anti-p-p38 antibodies (1:500, 1:500, and 1:200, respectively; Cell Signaling Technology) and goat anti-Ibal (1:400; Abcam) or mouse anti-neuronal-specific nuclear protein (NeuN) (1:1000; Millipore Bioscience Research Reagents) or mouse anti-GFAP (1:5000; Millipore Bioscience Research Reagents) antibody in PBS with $1 \%$ NGS. In naive rats, the anti-p-ERK1/2 antibody was amplified with biotinylated goat antirabbit IgG (1:1000; Vector Laboratories). These sections were then incubated for $1 \mathrm{~h}$ with Alexa Fluor 555-conjugated streptavidin and Alexa Fluor 488-conjugated donkey anti-goat or Alexa Fluor 488-conjugated goat anti-mouse antibody (1:1000; Invitrogen). In CCI rats, labeled sections were incubated with Alexa Fluor 555-conjugated donkey antirabbit and Alexa Fluor 488-conjugated donkey anti-goat or Alexa Fluor 488-conjugated goat anti-mouse antibody (1:1000; Invitrogen) antibodies. Spinal cord sections were washed, mounted in Vectashield (Vector Laboratories), and analyzed under a fluorescence microscope (Axio Imager M1; Carl Zeiss). Photographs were taken with a digital camera (Axio Cam HRC; Carl Zeiss) equipped with image acquisition software (Axio Vision; Carl Zeiss).

Quantification of immunohistochemical labeling. Spinal cord sections for one series (two sham-vehicle, two CCI-vehicle, and two CCIINCB3344) were successively photographed with the same camera parameters (Axio Vision; Carl Zeiss). We quantified 10-12 sections of L4-L5 spinal cord per animals from four sham-vehicle, four CCI-vehicle, and four CCI-INCB3344 rats. For the analysis of the effect of INCB3344 on the accumulation of p-ERK1/2-immunoreactivity (IR) in CCI rats, the same threshold gray level is applied to all sections of the same series, and the area of the p-ERK1/2-IR in a defined area of laminae I-III was quantified in a completely blind manner with NIH Image J software. Data are presented as relative unit areas with respect to control values (expressed as fold over sham value). Using the same software, we analyzed, in a completely blind manner, the effect of INCB3344 on Iba1-IR 
in CCI rats, by determining the mean grayscale level, which reflects the intensity of immunostaining in a defined area of laminae I-III.

\section{Electron microscopy}

Preembedding immunohistochemistry. Briefly, free-floating sections were incubated in $0.1 \mathrm{M}$ PBS supplemented with $3 \%$ NGS and $0.1 \%$ Triton $\mathrm{X}-100$ for $2 \mathrm{~h}$. They were incubated overnight at $4^{\circ} \mathrm{C}$ with rabbit polyclonal anti-CCL2 (1:500; Torrey-Pines Biolabs) antibody in $0.1 \mathrm{M}$ PBS supplemented with $1 \%$ NGS and then for $1 \mathrm{~h}$ with the secondary antibodies (1:1000 biotinylated goat anti-rabbit IgG; Vector Laboratories). The CCL2-labeled sections were washed three times in PBS and incubated with avidin-biotin horseradish peroxidase (HRP) (Vector Laboratories) for $1 \mathrm{~h}$. The peroxidase reaction was developed with $0.05 \%$ 3-3'diaminobenzidine (DAB) (Sigma) supplemented with $0.003 \%$ hydrogen peroxide in $0.05 \mathrm{M}$ Tris- $\mathrm{HCl}$ buffer, $\mathrm{pH}$ 7.6, for $5-10 \mathrm{~min}$. The free-floating sections were then incubated for 30 min with $0.5 \%$ glutaraldehyde, rinsed in $0.1 \mathrm{M}$ PBS, and postfixed by incubation at room temperature with $1 \%$ osmium tetroxide in $0.1 \mathrm{~m}$ cacodylate buffer, $\mathrm{pH}$ 7.4 , for $1 \mathrm{~h}$ at $4^{\circ} \mathrm{C}$. Sections were washed in cacodylate buffer, followed by $\mathrm{H}_{2} \mathrm{O}$, and were then incubated in uranyl acetate solution $\left(2 \%\right.$ in $\mathrm{H}_{2} \mathrm{O}$ for $15 \mathrm{~min}$ at room temperature). Sections were finally rinsed in $\mathrm{H}_{2} \mathrm{O}$ and then dehydrated in a series of alcohol concentrations. Sections were incubated in propylene oxide for $10 \mathrm{~min}$ and then with a mixture of propylene oxide/Epon resin (50:50) overnight, before embedding in pure Epon 812. The resin was allowed to polymerize, and ultrathin sections $(80 \mathrm{~nm})$ were cut with a Reichert-Jung ultramicrotome and collected on uncoated nickel grids.

Postembedding immunohistochemistry. Laminae I-II were cut from free-floating spinal cord sections, and tissue samples were dehydrated and embedded in Epon resin, as described above. Ultrathin sections (80 $\mathrm{nm}$ ) were then collected on uncoated nickel grids for immunohistochemistry. Briefly, the grid was incubated with $0.05 \mathrm{~m}$ glycine for $15 \mathrm{~min}$ and then washed in $0.1 \%$ Triton X-100 in $0.1 \mathrm{M}$ PBS. Grids were incubated in 5\% NGS and 5\% bovine serum albumin for $1 \mathrm{~h}$ and then with rabbit polyclonal anti-CCL2 antibody $(1: 500)$ for $24 \mathrm{~h}$ at $4^{\circ} \mathrm{C}$. The sections were thoroughly washed and placed on drops containing the secondary antibodies (biotinylated goat anti-rabbit at 1:1000). They were then rinsed again in $0.1 \mathrm{M}$ PBS and incubated with streptavidinconjugated $10 \mathrm{~nm}$ gold particles (1:40; Aurion) for $1 \mathrm{~h}$, rinsed in $0.1 \mathrm{M}$ $\mathrm{PBS}$ and $\mathrm{H}_{2} \mathrm{O}$, and dried. Sections were counterstained with uranyl acetate and lead citrate at room temperature. The grids were rinsed in $\mathrm{H}_{2} \mathrm{O}$ and dried before observation.

The ultrathin sections were examined by transmission electron microscopy (TEM), in a Phillips CM 120 operating at $120 \mathrm{kV}$. The transmission electron microscope used was equipped with a Morada digital camera. EM images were captured with the CCD camera, using iTEM Olympus software. TIFF images were prepared for publication with Adobe Photoshop (Adobe Systems) vCS3 running on a Macintosh computer (Apple Computers).

\section{Superfusion of the dorsal horn of the spinal cord slices}

Rats were decapitated, and the dorsal part of the lumbar enlargement of the spinal cord was dissected at $0^{\circ} \mathrm{C}$, as described previously (Cesselin et al., 1984; Mauborgne et al., 1987). For each experiment, spinal samples from six rats were maintained in an artificial CSF (aCSF) (in mm: 136.0 $\mathrm{NaCl}, 16.2 \mathrm{NaHCO}_{3}, 5.4 \mathrm{KCl}, 1.2 \mathrm{NaH}_{2} \mathrm{PO}_{4}, 2.2 \mathrm{CaCl}_{2}, 1.2 \mathrm{MgCl}_{2}, 10.5$ $\mathrm{Na}_{2} \mathrm{SO}_{4}$, and 5.0 glucose [adjusted to $\mathrm{pH} 7.3$ by bubbling with a $95: 5(\mathrm{v} / \mathrm{v})$ mixture of $\mathrm{O}_{2}$ and $\left.\mathrm{CO}_{2}\right]$ ) and then transferred onto a filter paper and sliced (thickness, $0.3 \mathrm{~mm}$ ) with a McIlwain tissue chopper. The slices were pooled in $6.5 \mathrm{ml}$ of aCSF and evenly distributed in six thermostatically controlled $\left(37^{\circ} \mathrm{C}\right)$ Plexiglas chambers. Samples were continuously superfused with the experimental medium at a flow rate of $0.25 \mathrm{ml} / \mathrm{min}$. They were then washed for $30 \mathrm{~min}$, and 12 or 16 successive $1 \mathrm{ml}$ superfusate fractions were collected in polystyrene tubes every $4 \mathrm{~min}$, maintained at $0^{\circ} \mathrm{C}$, and immediately divided into aliquots for storage at $30^{\circ} \mathrm{C}$ until CCL2 measurements. $\mathrm{KCl}$ concentration was increased to $30 \mathrm{~mm}$, whereas $\mathrm{NaCl}$ concentration was decreased to $111.4 \mathrm{~mm}$, to depolarize the tissues and trigger the $\mathrm{Ca}^{2+}$-dependent release of peptides (Mauborgne et al., 1987; Pohl et al., 1989b) for $8 \mathrm{~min}$, from $t=12-20 \mathrm{~min}$. The basal rate of CCL2 secretion was estimated by calculating the area under the curve (AUC) for fractions 0 to $12 \mathrm{~min}$. The $\mathrm{K}^{+}$-stimulated rate of CCL2 secretion was estimated by calculating the area under the curve for fractions 12 to 48 or $64 \mathrm{~min}$ and subtracting the basal rate of CCL2 secretion.

\section{ELISA}

Triton X-100 (0.5\% final concentration) was added to each fraction collected before ELISA, and samples were sonicated for $5 \mathrm{~min}$. CCL2 was quantified with the OptiEIATM ELISA Set (BD Biosciences). Absorbance was read at $450 \mathrm{~nm}$ and corrected at $570 \mathrm{~nm}$. ELISA was performed in accordance with the instructions of the manufacturer.

\section{$R T-q P C R$}

RNA extraction. Total RNA was extracted from frozen pieces of tissue with the NucleoSpin RNA II Purification kit (Macherey-Nagel), and its quality and concentration were evaluated from absorbance measurements with NanoDrop (Thermo Fisher Scientific, Labtech).

$R T-q P C R$. For real-time RT-PCR analysis, first-strand cDNA synthesis $(0.6 \mu \mathrm{g}$ of total RNA per $20 \mu \mathrm{l}$ reaction) was performed with a HighCapacity cDNA Reverse Transcription kit (Applied Biosystems). Real-time PCR amplification of each sample was performed in triplicate, on an ABI Prism 7300 (Applied Biosystems), with the ABgene Absolute QPCR ROX Mix (ABgene). Assay-on-Demand Gene TaqMan PCR probes (Applied Biosystems) were used for target genes: ITGAM (Rn00709342_m1), GFAP (Rn01460868_m1), IL6(Rn00561420_m1), IL1 $\beta$ (Rn00580432_m1), CCL2 (Rn00580555_m1), COX2 (Rn00568225_m1), NOS2 (Rn00561646_m1), and glyceraldehyde-3-phosphate dehydrogenase (GAPDH) (Rn99999916_s1). Specific mRNA levels were calculated after normalization of the results for each sample with those for GADPH mRNA. The data are presented as relative mRNA units with respect to control values (expressed as fold over sham value).

\section{Western blotting}

Protein extraction. Frozen tissue pieces were homogenized on ice in 200 $\mu \mathrm{l}$ of radioimmunoprecipitation assay buffer [20 mM Tris, $\mathrm{pH} 7.5,150$ mм NaCl, 1\% NP40 (VWR), 0.5\% sodium deoxycholate, 1 mм EDTA, and $0.1 \%$ SDS] supplemented with proteases and phosphatase inhibitor cocktails (Sigma-Aldrich). Samples were centrifuged $(10,000 \times g, 10$ $\min , 4^{\circ} \mathrm{C}$ ), and the supernatants were collected and centrifuged again.

Western blotting procedure. Equal amounts of protein $(40 \mu \mathrm{g})$, as determined by Bio-Rad protein assays, were diluted with NuPAGE sample reducing agent (10×; Invitrogen) and NuPAGE LDS sample buffer $(4 \times$; Invitrogen) in water, heated at $95^{\circ} \mathrm{C}$ for $1 \mathrm{~min}$, and then separated by SDS-PAGE (4-12\% Bis-Tris Gel; Invitrogen). Proteins were then electrotransferred (iBlot; Invitrogen) onto a nitrocellulose membrane (iBlot Gel Transfer Stacks Nitrocellulose; Invitrogen). The membrane was first saturated by incubation in blocking solution ( $5 \%$ bovine serum albumin and $0.1 \%$ Tween 20 in PBS) for $1 \mathrm{~h}$ and was then incubated overnight at $4^{\circ} \mathrm{C}$ with rabbit polyclonal anti-p-p44/42 MAPK or rabbit polyclonal anti-p-AKT or rabbit polyclonal anti-p-p38 antibodies (1:500, 1:500, and 1:200, respectively; Cell Signaling Technology) and mouse monoclonal anti- $\alpha$-tubulin antibody (1:10,000; GE Healthcare) in blocking solution. Blots were rinsed with $0.1 \%$ Tween 20 in PBS and incubated for $1 \mathrm{~h}$ with biotinylated goat anti-rabbit IgG (1:1000; Vector Laboratories) and HRP-conjugated anti-mouse (1:5000; Sigma-Aldrich) antibodies in blocking solution. The blots were washed several times, incubated for $1 \mathrm{~h}$ in streptavidin-HRP (1:1000; Sigma-Aldrich), and finally washed in PBS. Membranes were processed with the ECL Plus kit (GE Healthcare), and the proteins of interest were investigated with an Ettan DIGE Imager (GE Healthcare) coupled to acquisition software. The immunoreactivity of p-p42 and p-p44 was compared with that of $\alpha$-tubulin controls and quantified based on scanned images of the blots, with NIH image J software (http://rsb.info.nih.gov/ij/).

\section{Mechanical allodynia measurement}

Stress as a result of experimental conditions was avoided by ensuring that all manipulations were performed in quiet conditions, in a test room, by the same experimenter. In the $5 \mathrm{~d}$ leading up to experiments, animals 
were placed in the test room for $1 \mathrm{~h} / \mathrm{d}$ (from 9:00 A.M. to 10:00 A.M.), before acclimation in suspended cages with a wire mesh bottom.

In naive rats. Mechanical allodynia was assessed using an automatic von Frey dynamic plantar anesthesiometer (Ugo Basil) as described previously (Dansereau et al., 2008). On the test day, the baseline threshold of naive rats was evaluated, and then animals were anesthetized before an intrathecal injection of vehicle or PD98059, followed 30 min later by an intrathecal injection of saline or CCL2. Mechanical allodynia was evaluated $4 \mathrm{~h}$ after the second injection.

In SN-CCI rats. Mechanical allodynia was evaluated on the day before the surgery and $14 \mathrm{~d}$ after surgery. Three successive intrathecal injections of INCB3344 or vehicle were performed at $24 \mathrm{~h}$ intervals (15, 16, and $17 \mathrm{~d}$ after surgery), and mechanical allodynia was evaluated daily $2 \mathrm{~h}$ after intrathecal injection. Behavioral analyses were performed with von Frey's test, which was performed in a completely blind manner.

Mechanical allodynia was determined as described previously (Chaplan et al., 1994). The ipsilateral and contralateral hindpaws were probed with calibrated von Frey filaments (Stoelting) applied perpendicularly to the plantar surface and held in position for $\sim 5 \mathrm{~s}$. A positive response was indicated by a sharp withdrawal of the paw. The $50 \%$ paw-withdrawal threshold was determined by a nonparametric method, with incremental increases in the stimulus until a positive response was obtained, followed by decreases until a negative result was obtained. The protocol was repeated until three changes in behavior had been determined and the pattern of positive and negative responses was recorded. The 50\% pawwithdrawal threshold was determined as $[10(X f$ $+k D)] / 10,000$, where $X f$ is the value of the last von Frey filament used, $k$ is Dixon value for the positive/negative pattern, and $D$ is the logarithmic difference between stimuli.

\section{Statistical analysis}

All values are expressed as means \pm SEM. CCL2 release was analyzed by two-way ANOVA for repeated measures, followed by Bonferroni's post hoc tests. Data for the basal and $\mathrm{K}^{+}$-stimulated CCL2 secretion rates were analyzed by calculation of the AUC and comparisons based on Student's $t$ test. qPCR, Western blotting, and immunohistochemical data were analyzed by one-way ANOVA, followed by StudentNewman-Keuls post hoc tests, except analysis of CCL2mRNA in DRG and DHSC of SN-CCI rats at different times after surgery in which oneway ANOVA followed by Dunnett's post hoc tests were performed. For behavioral tests, data were analyzed by two-way ANOVA, followed by Bonferroni's post hoc tests and Student's $t$ tests for comparisons of shamoperated rats and SN-CCI rats $14 \mathrm{~d}$ after surgery, before treatment. Statistical analyses were performed with Prism 5 GraphPad software.

\section{Results}

Electron microscopy localization of CCL2 in the rat DHSC by preembedding and postembedding immunohistochemistry Under the electron microscope, sections processed in the absence of the primary antibody against CCL2 displayed no immunogold or immunoperoxidase labeling for CCL2 (data not shown). Within laminae I-II of the DHSC, CCL2-IR was found principally in a presynaptic position, in axon terminals. Immunogoldlabeled particles (10 $\mathrm{nm}$ diameter) and immunoperoxidase
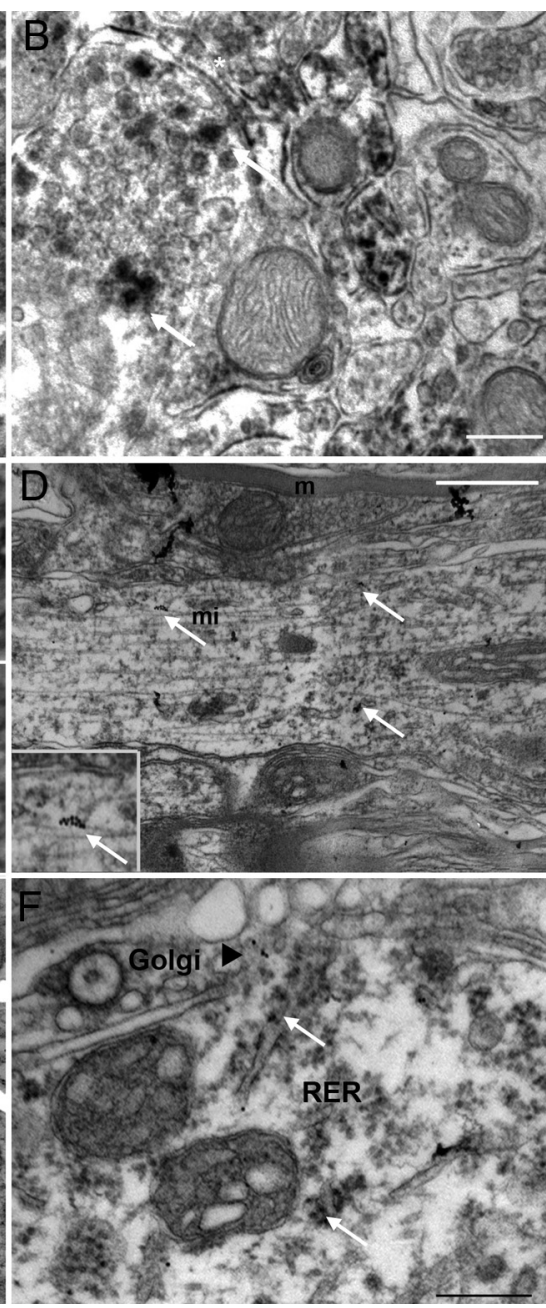

Figure 1. Subcellular distribution of CCL2 immunolabeling in the DHSC. $A-E$, Postembedding and preembedding electron micrographs showing the distribution of $C C L 2-I R$ elements in the dorsal spinal cord. $A, B, D A B$ precipitate or immunogold particles (arrows), in thinly myelinated (m) axons. $\boldsymbol{E}_{,}$CCL2-IR (arrows) is detected in central boutons of type II (CII), which make asymmetric synaptic contacts (asterisks) on several dendrites (D). $\boldsymbol{F}$, Immunolabeling for CCL2 is observed in the Golgi apparatus (arrowhead) and in the rough endoplasmic reticulum (RER) (arrows) of spinal neurons. Scale bars: $A, B, E, 0.5 \mu \mathrm{m} ; C, F, 0.25 \mu \mathrm{m} ; \boldsymbol{D}, 1 \mu \mathrm{m}$.

labeling corresponding to CCL2 were associated with two types of synaptic vesicle in small asymmetric synapse-forming terminals: large dense-core vesicles (DCV) (Fig. 1 $A, B$ ) and small clear vesicles (SCV) (Fig. 1C). In addition, immunogold particles appeared to be attached to the microtubule network (Fig. 1D), suggesting that CCL2 is transported along the spinal axons. CCL2-IR was also found in both unmyelinated (Fig. 1B) and thinly myelinated (Fig. $1 D$ ) axons of the DHSC. Nociceptive primary afferent $\mathrm{A} \delta$ and $\mathrm{C}$ fibers terminate principally in laminae I-II of the DHSC and form scalloped central terminals surrounded by numerous peripheral dendrites and axon terminals, the so-called synaptic glomerulus (Ribeiro-da-Silva and Coimbra, 1982; Coimbra et al., 1984; Maxwell et al., 1990). Ultrastructural examination showed that central glomerular boutons classified as type II on the basis of their round shape and the presence of numerous mitochondria (Fig. $1 E$ ) contained synaptic vesicles decorated with CCL2 gold particles. These central CCL2-IR boutons formed synaptic contacts with adjacent dendrites (D1, D2, D3), which were also immunoreactive for CCL2 (axo-dendritic synapses) (Fig. $1 E$, arrowheads). Finally, CCL2-IR was associated with the 
A

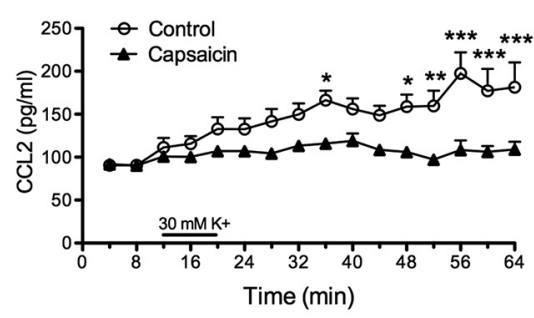

B

Basal

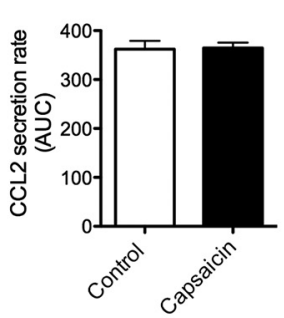

K+-stimulated-Basal

SN-CCI rats
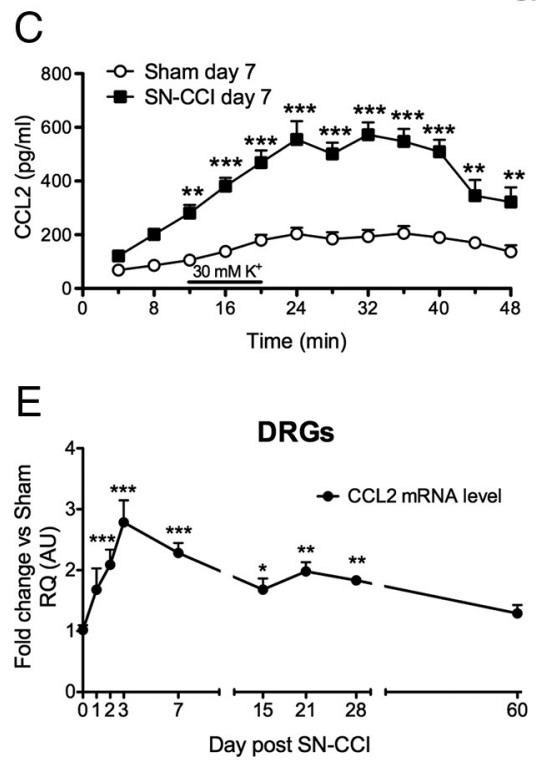

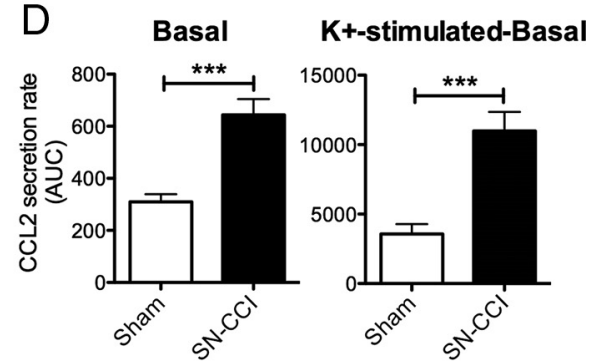

F

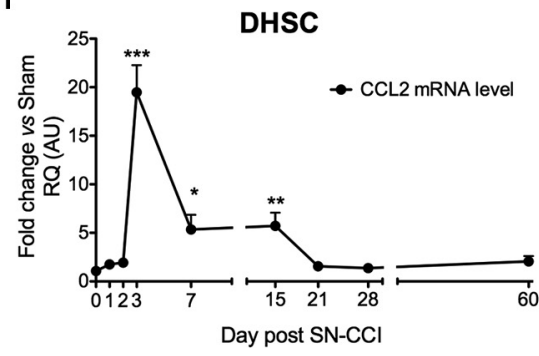

Figure 2. CCL2 secretion from DHSC explants from adult rats after neonatal capsaicin treatment or SN-CCl; $C \mathrm{CL} 2 \mathrm{mRNA}$ levels in the DRG and DHSC from SN-CCI. $A$, Concentration of CCL2 in superfusates of DHSCs from control (open circles) and neonatal capsaicin-treated (filled triangles) rats under basal or depolarization $\left(\mathrm{K}^{+}\right)$conditions. B, AUC of basal or $\mathrm{K}^{+}$-evoked $\mathrm{CCL} 2$ secretion in control or capsaicin-treated rats. Note that basal secretion levels of CCL2 were similar in control and capsaicin-treated animals, whereas $\mathrm{K}^{+}$-induced $\mathrm{CCL} 2$ release was significantly lower, by $\sim 65 \%$, in capsaicin-treated rats than in control animals. C, CCL2 concentration in superfusates of DHSCs from sham-operated (open circles) and SN-CCI (filled squares) rats under basal or depolarization $\left(\mathrm{K}^{+}\right)$conditions. D, AUC of basal or $\mathrm{K}^{+}$-stimulated CCL2 secretion in sham and SN-CCI rats. Note that both basal and $\mathrm{K}^{+}$-induced levels of CCL2 release were significantly higher in $\mathrm{SN}$-CCl rats than in sham-operated animals. $\boldsymbol{E}, \boldsymbol{F}$, Real-time qRT-PCR analysis $(0,1,3,7,15,21,28$, and $60 \mathrm{~d}$ after surgery) of CCL2 mRNA levels in ipsilateral L4-L6 DRGs (E) and the ipsilateral lumbar DHSC $(\boldsymbol{F})$ of SN-CCl rats. Note that SN-CCl induced the upregulation of CCL2 mRNA levels in the DRG and DHSC. Data are shown as means \pm SEM. $n=8-9$ for each group in superfusion experiments. We performed a two-way ANOVA for repeated measures, followed by the Bonferroni's post hoc test: ${ }^{*} p<0.05$, ${ }^{* *} p<0.01$, and ${ }^{* * *} p<0.001$. For AUC, Student's t test was used: ${ }^{* *} p<0.01$ and ${ }^{* * *} p<$ $0.001 . n=4-11$ for each time point examined in RT-qPCR studies. One-way ANOVA followed by the Dunnett's post hoc test: ${ }^{*} p<0.05$, ${ }^{* *} p<0.01$, and ${ }^{* * *} p<0.001$ was used to compare each time after surgery with day $0 . \mathrm{RQ}$, Relative quantification.

rough endoplasmic reticulum (Fig. $1 F$, arrows) and tubules of the Golgi apparatus in spinal neurons.

\section{CCL2 secretion from rat DHSC reflects changes in CCL2 mRNA levels in the DRG and spinal cord \\ Neonatal capsaicin-treated rats}

The detection of CCL2-IR in primary afferent fibers and in secretory vesicles in the DHSC strongly suggests that CCL2 may be transported and subsequently secreted from central terminals of primary afferents. We assessed the amount of CCL2 coming from DRG afferents, by destroying TRPV1-containing primary sensory fibers by neonatal capsaicin treatment and measuring CCL2 mRNA levels in the DHSC and DRG and CCL2 secretion from DHSC explants 3 months later, comparing the results obtained with those for control rats. Capsaicin treatment did not affect CCL2 mRNA levels in the DHSC (levels similar to those for con- trols, at $\times 0.96 \pm 0.19$ and $1.00 \pm 0.12$, respectively). In contrast, in the DRG of capsaicin-treated rats, CCL2 mRNA levels were $\sim 40 \%$ lower than those in control rats $(\times 0.61 \pm 0.11$ vs $1.01 \pm 0.08, n=4)$.

Interestingly, CCL2 release from the DHSC in response to neonatal capsaicin treatment reflected the change in CCL2 expression (Fig. 2A). Basal levels of CCL2 secretion from DHSC explants were similar in control and capsaicin-treated animals $(362.3 \pm 16.8$ and $364.4 \pm 11.1$ AUC, respectively) (Fig. $2 \mathrm{~B}$ ). In contrast, $\mathrm{K}^{+}$-induced tissue depolarization triggered the robust release of CCL2 in normal animals $(1866.0 \pm 403.5$ AUC, $n=$ 8 ), with levels $\sim 65 \%$ lower in capsaicintreated rats $(686.7 \pm 118.5$ AUC, $p<0.01$, $n=9$ ) (Fig. 2B).

\section{SN-CCI rats}

We further examined changes in CCL2 mRNA levels in the DHSC and DRG, and changes in CCL2 release from the DHSC in animals after SN-CCI. We found that SN$\mathrm{CCI}$ resulted in the prolonged upregulation of CCL2 mRNA production in both the DRG and DHSC ipsilateral to the injured nerve (Fig. 2E, F). CCL2 mRNA levels in the DRG were significantly upper in SN-CCI animals than in sham-operated animals $2 \mathrm{~d}$ after surgery $(\times 2.09 \pm 0.25, p<0.001, n=$ $8)$. This difference between the two groups was maximal $3 \mathrm{~d}$ after the intervention $(\times 2.78 \pm 0.36, p<0.001, n=5)$, gradually decreasing thereafter until the SN-CCI values attained the sham-operated group $(\times 1.29 \pm 0.14, n=4) 60 \mathrm{~d}$ after the intervention. In the DHSC of SN-CCI rats, CCL2 mRNA levels were maximal on day 3 $(\times 19.47 \pm 2.80, p<0.001, n=5)$. By 7 and $15 \mathrm{~d}$ after surgery, CCL2 mRNA levels remained high but were lower than peak values $(\times 5.35 \pm 1.51, p<0.05, n=7$ and $\times 5.71 \pm 1.37, p<0.01, n=11$, respectively). They returned to control values by $21 \mathrm{~d}$ after surgery $(\times 1.56 \pm 0.18, n=5)$.

In animals undergoing SN-CCI surgery, CCL2 release from the DHSC (ipsilateral to the nerve lesion) was evaluated $7 \mathrm{~d}$ after surgery, when CCL2 mRNA levels were approaching a plateau in both the DRG and DHSC. In SNCCI animals, basal CCL2 release levels were approximately twice those in sham animals $(643.7 \pm 60.8$ vs $309.6 \pm 29.3$ AUC, $p<$ $0.001, n=9)$ and were approximately three times higher in conditions of tissue depolarization $(10,986.0 \pm 1376.1$ vs $3563.0 \pm$ 719.9 AUC, $p<0.001, n=9$ ) (Fig. 2D).

Spinal cord neuroinflammation and ERK pathway activation associated with $\mathrm{SN}-\mathrm{CCI}$ or induced by the spinal injection of exogenous CCL2 are inhibited by the intrathecal administration of CCR 2 antagonist

$\mathrm{SN}-\mathrm{CCI}$ resulted in microglial activation [increase in ITGAM (microglial marker) mRNA levels of $\times 2.95 \pm 0.24, p<0.001, n=7$ with 
respect to sham-operated animals, $n=5$ ] (Fig. $3 F$ ) and higher levels of mRNA for several key proinflammatory and proalgesic factors: $\operatorname{IL} 1 \beta(\times 3.80 \pm 0.55, p<0.001, n=$ $14), \operatorname{COX} 2(\times 1.72 \pm 0.17, p<0.01, n=14)$, NOS2 $(\times 16.36 \pm 4.68, p<0.01, n=14)$, and CCL2 $(\times 7.34 \pm 1.80, p<0.001, n=$ $14)$ in the rat DHSC than in the corresponding sham-operated animals $(n=12)$ (Fig. $3 A, C-E)$. We assessed the involvement of endogenous CCR2 in the upregulated production of these proinflammatory and proalgesic mediators, by analyzing the effect of three successive intrathecal injections of 1 mM INCB3344 (CCR2 antagonist) or vehicle, at $24 \mathrm{~h}$ intervals, between 15 and $17 \mathrm{~d}$ after surgery. INCB3344 treatment significantly decreased the upregulation of $\operatorname{IL} 1 \beta$, COX2, NOS2, and CCL2 mRNA levels (Fig. $3 A, C-E)$ in the DHSC $[\times 1.74 \pm 0.24, p<$ $0.001,(-78.8 \%), n=12 ; \times 0.93 \pm 0.15$, $p<0.01,(-100 \%), n=12 ; \times 1.57 \pm 0.42$, $p<0.01,(-99.2 \%), n=12$; and $\times 2.941 \pm$ $0.77, p<0.05,(-73.1 \%), n=12$, respectively, with respect to vehicle-treated $\mathrm{SN}$ CCI animals, $n=12$ ]. Treatment with a CCR2 antagonist only partly decreased (by $40 \%)$ the upregulation of ITGAM mRNA levels $(\times 2.18 \pm 0.08, p<0.05, n=5$ ) (Fig. $3 F)$ and had no significant effect on the upregulation of IL6 mRNA levels in the DHSC of SN-CCI rats (Fig. 3B).

The intrathecal administration of exogenous CCL2 $(1 \mu \mathrm{g} / \mathrm{rat})$ in naive rats mimicked the upregulated expression of proinflammatory/proalgesic markers observed in the DHSC of SN-CCI animals. IL1 $\beta$, IL6, COX2, and CCL2 mRNA levels were markedly higher in the DHSC $2 \mathrm{~h}$ after CCL2 injection than in salineinjected rats (Fig. 3G-I,K), by factors of $13.71 \pm 5.45(p<0.01), 31.71 \pm 12.76$ $(p<0.01), 3.58 \pm 0.75(p<0.01)$, and $21.6 \pm 6.95(p<0.001)$ ( $n=5-9$ per group), respectively. The pretreatment of animals with $1 \mathrm{~mm}$ INCB3344 (CCR2 antagonist) before CCL2 administration completely prevented these effects. Intrathecal injection of INCB3344 alone had no effect on the mRNA levels of the proinflammatory factors studied (Fig. $3 G-I, K$ ). These data suggest that the CCR2 receptor is directly involved in the CCL2mediated upregulation of several markers associated with spinal cord neuroinflammation. In contrast, the intrathecal injection of CCL2 had no effect on spinal levels of NOS2, ITGAM (Fig. $3 \mathrm{~J}, \mathrm{~L}$ ), or GFAP mRNA (data not shown) or on immunoreactivity for Ibal or GFAP (data not shown), $2 \mathrm{~h}$ after the injection.

The rapid induction of proinflammatory marker expression by the intrathecal injection of CCL2 in naive rats led us to investigate whether CCL2 could also trigger the activation of intracellular pathways known to play an important role in tissue plasticity and inflammatory responses. We investigated the impact of intrathecal administration of $1 \mu \mathrm{g}$ of CCL2 on the AKT (data not shown), MAPK p38 (data not shown), and ERK1/2 pathways in naive rats. Only the ERK1/2 pathway was found to be activated. Indeed, exogenous CCL2 induced a rapid $(1 \mathrm{~h}$ after

\section{CCL2-injected rat DHSC}
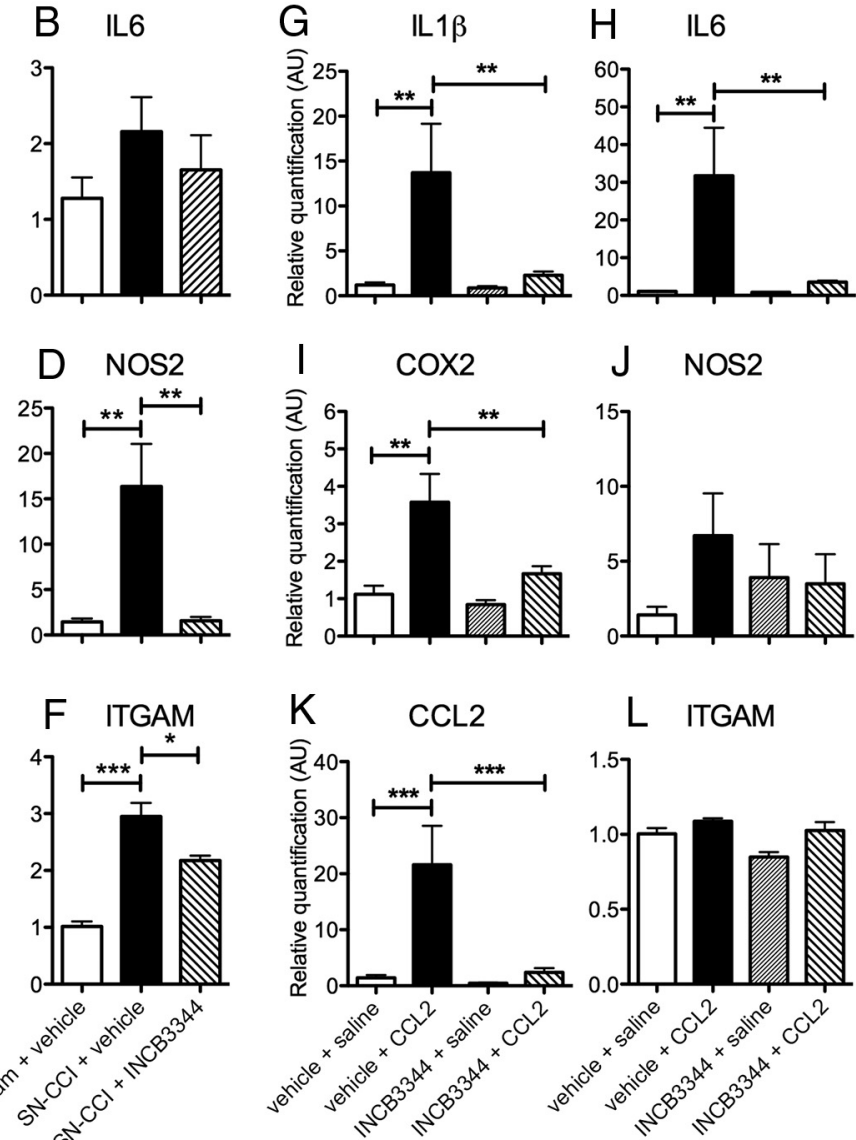

L ITGAM
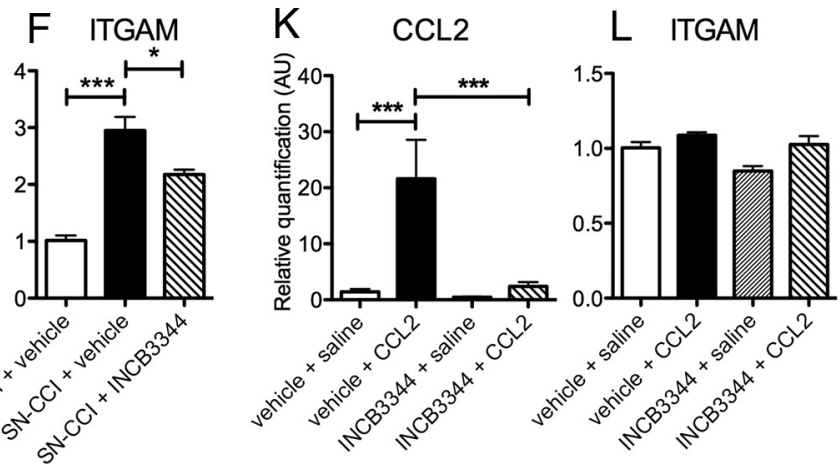

Figure 3. Effect of intrathecal CCR2 antagonist on mRNA levels of markers associated with spinal neuroinflammatory context in SN-CCl rats or induced by exogenous spinal CCL2 in naive rats. $\boldsymbol{A}-\boldsymbol{F}, \mathrm{RT}-\mathrm{qPCR}$ analysis of the effect of three intrathecal injections (on 至 ( levels are presented as a fold change relative to vehicle/saline-injected rats or sham vehicle-treated rats after normalization with respect to the housekeeping gene (GAPDH). Each bar is the mean \pm SEM. $n=5-14$ animals/group. We performed a one-way ANOVA, followed by the Student-Newman-Keuls post hoc test: ${ }^{*} p<0.05,{ }^{* *} p<0.01$, and ${ }^{* * *} p<0.001$.

injection) accumulation of the phosphorylated (active) form of ERK1/2-IR (p-ERK1/2) in superficial layers of the spinal cord (Fig. 4A). This activation was further confirmed and quantified by Western blotting (p-ERK1, 67.68 \pm 8.90 AU vs vehicle + saline rats, $41.03 \pm 1.30 \mathrm{AU}, p<0.05$; and $\mathrm{p}-\mathrm{ERK} 2,41.15 \pm 6.14$ $\mathrm{AU}$ vs vehicle + saline rats, $11.17 \pm 4.03 \mathrm{AU}, p<0.05, n=3$ per group) (Fig. $4 B, C$ ). Double immunolabeling for specific markers of neurons (NeuN), astrocytes (GFAP), and microglia (Iba1) showed that p-ERK1/2-IR accumulated in both spinal cord neurons and microglial cells (Fig. $4 A$ ) but not in astrocytes (data not shown). The exogenous CCL2-induced phosphorylation of both ERK1 (p44) and ERK2 (p42) in rat DHSC was clearly mediated by CCR2, because the previous treatment of animals ( $1 \mathrm{~h}$ before CCL2 injection) with $1 \mathrm{~mm}$ INCB3344, a CCR2 antagonist, almost completely blocked this effect (p-ERK1, $44.18 \pm 5.68 \mathrm{AU}$ and p-ERK2, $19.95 \pm 6.38 \mathrm{AU}, p<0.05$ vs vehicle + CCL2 rats, $n=4$ ) (Fig. $4 B, C$ ). Intrathecal injection of INCB3344 alone had no effect on p-ERK1/2 levels (Fig. $4 B$ ).

We further evaluated the possible involvement of the CCL2/ CCR2 system in the activation of intracellular pathways in pathological (SN-CCI) conditions. In particular, because our data 


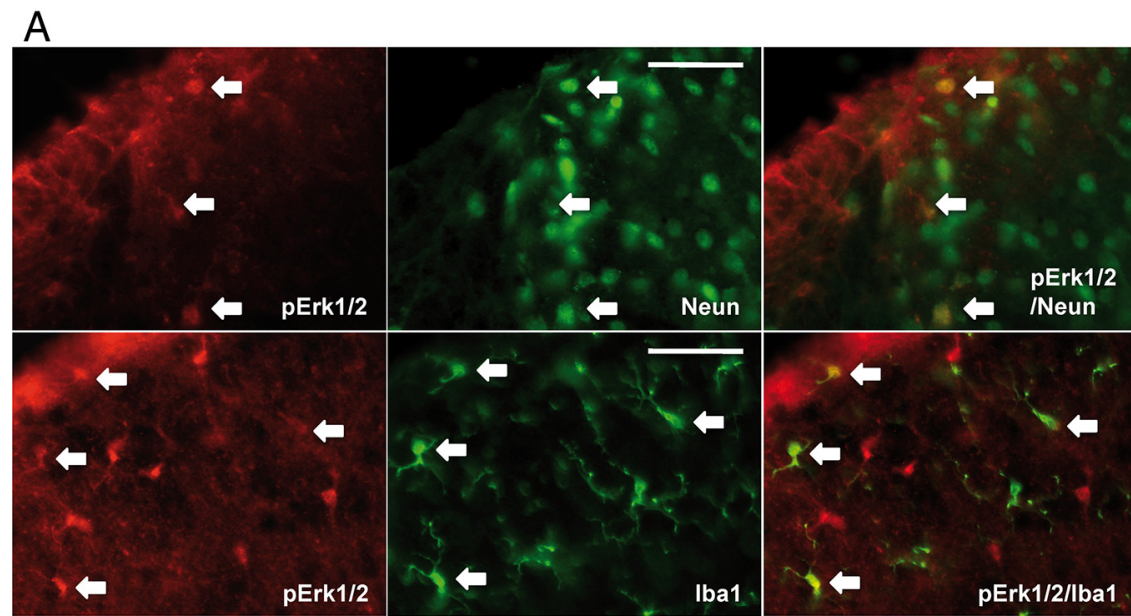

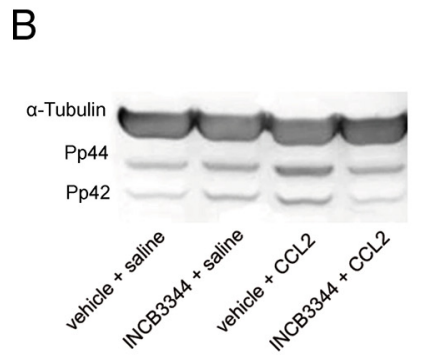

$\mathrm{D}$

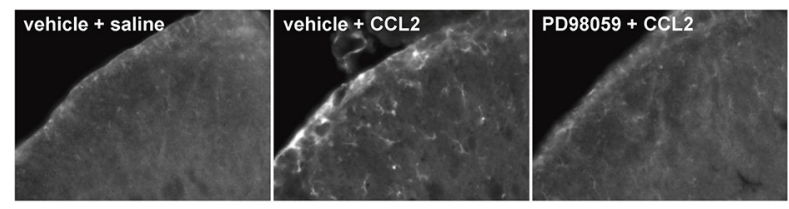

C

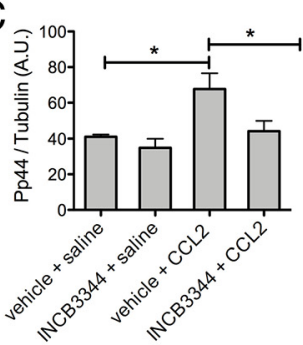

$E$

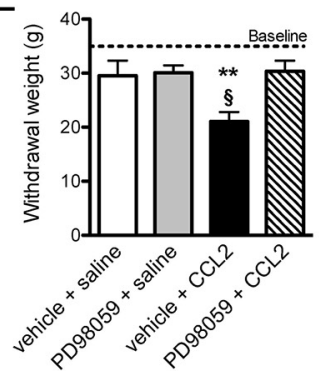

Figure 4. Intrathecal injection of CCL2 induces mechanical allodynia via activation of the activation of ERK1/2 pathway in the DHSC of naive rats. $A$, Double-immunofluorescent labeling $p$-ERK1/2/NeuN or $p$-ERK1/2/lba1 in DHSC of CCL2-treated rats. Scale bar, $100 \mu \mathrm{m} . B$, C, Western blot analysis of p-ERK1 (p-p44) and p-ERK2 (p-p42) accumulation in DHSC of naive rats $1 \mathrm{~h}$ after intrathecal injection of saline or CCL2 $(1 \mu \mathrm{g})$ in animals pretreated or not with $1 \mathrm{~mm}$ INCB3344. Mean gray levels of $p$-ERK1 and $\mathrm{p}$-ERK2 were normalized to the housekeeping protein ( $\alpha$-tubulin). Note that CCL2-induced accumulation of $\mathrm{p}$-ERK1/2 in rat DHSC was almost completely blocked by $1 \mathrm{~h}$ earlier intrathecal pretreatment with CCR2 antagonist INCB3344. Data are shown as mean \pm SEM of three independent experiments. One-way ANOVA, followed by Student-Newman-Keuls post hoc test was used: ${ }^{*} p<$ 0.05. D, E, Effect of PD98059, a MEK1 inhibitor on CCL2-induced p-ERK1/2 and mechanical allodynia. Intrathecal injection of PD98059 $(10 \mu \mathrm{g})$ or vehicle was performed 30 min before injection of CCL2 $(1 \mu \mathrm{g})$ or saline. $\boldsymbol{D}$, Immunofluorescent labeling p-ERK1/2 in DHSC. Pretreatment with PD98059 inhibits CCL2-induced p-ERK1/2-IR in DHSC. E, Mechanical allodynia was evaluated using von Frey dynamic plantar anesthesiometer. Note that pretreatment with PD98059 inhibits CCL2-induced mechanical allodynia. The dotted line represents the baseline before injections $(n=20)$. Each bar is the mean \pm SEM $(n=$ 4-6 per groups) of withdrawal weight (grams) $4 \mathrm{~h}$ after the second injection. Two-way ANOVA for repeated measures followed by Bonferroni's post hoc test was used: ${ }^{\circledR} p<0.05$, vehicle $+C C L 2$ versus vehicle + saline; ${ }^{* *} p<0.01$, PD 98059 $+C \mathrm{CL} 2$ versus vehicle $+\mathrm{CCL} 2$.

were consistent with a direct role for CCL2 in ERK phosphorylation, we focused principally on the ERK1/2 MAPK pathway. The data obtained for sham-operated or SN-CCI rats and for shamoperated or SN-CCI rats injected intrathecally with vehicle were very similar. For clarity, we present the data for the vehicletreated rats only. Seventeen days after surgery, p-ERK1/2-IR was almost undetectable in the ipsilateral DHSC of sham-operated rats (Fig. 5A) and on the side contralateral (data not shown) to the injured sciatic nerve in SN-CCI rats. In the ipsilateral DHSC of SN-CCI rats, p-ERK1/2-IR accumulated in superficial and me- dial laminae (I-III), the area immunolabeled being $3.56 \pm 0.87(n=4)$ times larger than for basal p-ERK1/2-IR labeling in sham-operated rats. Double immunolabeling for specific markers of neurons, astrocytes, and microglia showed that p-ERK1/2-IR was restricted to Iba1-labeled microglial cells in SN-CCI rats (Fig. 5A). No p-ERK1/2-IR was observed, at least on day 17 after surgery, in the spinal cord neurons or astrocytes of SN-CCI rats (data not shown). At the same time point (17 d after surgery), dense Ibal labeling was also observed in the ipsilateral dorsal horn of SN-CCI animals, indicating microglial cell activation in this area (Fig. 5B).

The implication of CCL2 in ERK1/2 pathway activation was evaluated by treating $\mathrm{SN}-\mathrm{CCI}$ animals with intrathecal CCR2 antagonist, as described above (injection of $1 \mathrm{~mm} \mathrm{INCB3344} \mathrm{per} \mathrm{day} \mathrm{on} 3$ consecutive days). The repeated administration of INCB3344 completely abolished p-ERK1/2-IR accumulation in the spinal microglia of SN-CCI rats (Fig. 5A). Moreover, this treatment also significantly attenuated (by $\sim 50 \%$ ) microglial activation, as demonstrated by the lower level of Ibal immunostaining in the spinal cord of INCB3344-treated rats than that in sham-treated SN-CCI rats (67.35 \pm 2.52 vs $94.70 \pm 5.83$, respectively, $p<$ $0.05, n=3$ per group) (Fig. $5 B$ ).

\section{CCL2-induced $\mathrm{p}$-ERK1/2 and mechanical hypersensitivity are abolished by MEK1 inhibitor}

To establish an eventual link between the CCL2-evoked activation of ERK1/2 pathway and induction of pain, we evaluated the effect of pretreatment with MEK1 inhibitor (PD98059) on ERK1/2 pathway activation in DHSC and on mechanical allodynia. As shown in Figure $4 D$, pretreatment with PD98059 completely prevented the CCL2-induced accumulation of p-ERK1/2-IR in DHSC. Cell types containing p-ERK1/2 immunoreactivity in DHSC, $4 \mathrm{~h}$ after CCL2 injection, were identical to those observed $1 \mathrm{~h}$ after CCL2 administration (cf. Fig. $4 A$ ), i.e., neurons and microglia (data not shown).

The basal withdrawal weight threshold, measured using von Frey dynamic plantar anesthesiometer before injections, was $34.59 \pm 0.94 \mathrm{~g}(n=20)$ (Fig. 4E). Four hours after an intrathecal injection of $1 \mu \mathrm{g}$ of CCL2, rats showed a significant reduction of withdrawal weight threshold $(21.04 \pm 1.77 \mathrm{~g}, n=5, p<0.05)$ compared with vehicle + saline-injected rats $(29.56 \pm 2.76 \mathrm{~g}, n=$ 5). This CCL2-induced mechanical allodynia was completely prevented in animals pretreated with $10 \mu \mathrm{g}$ of PD98059 (withdrawal weight threshold of PD98059 + CCL2 rats, $30.35 \pm$ $1.96 \mathrm{~g}, n=6, p<0.01)$. Intrathecal injection of PD98095 
alone (PD98059 + saline) did not affect the withdrawal weight threshold (30.08 \pm $1.36 \mathrm{~g}, n=4)$.

The CCR2 antagonist INCB3344 attenuated established mechanical allodynia in SN-CCI rats

The mechanical nociceptive threshold of rats was evaluated with von Frey filaments at various times after sham or SN-CCI surgery. From day 14 after surgery, SN-CCI rats had a significantly lower weight threshold for stimuli applied to the left hindpaw (the side of sciatic nerve constriction) than shamoperated animals (SN-CCI, $7.11 \pm 0.90 \mathrm{~g}$, $n=17$; sham rats, $13.80 \pm 0.76 \mathrm{~g} ; p<0.001$; $n=6)$. Weight thresholds did not differ significantly between the two groups of SNCCI rats randomly chosen for vehicle or CCR2 antagonist injections (vehicle-injected SN-CCI rats, $7.71 \pm 0.76 \mathrm{~g}, n=9$; and INCB3344-injected SN-CCI rats, $6.43 \pm$ $1.05 \mathrm{~g}, n=8)$. Repeated intrathecal injections of INCB3344 (1 mM) significantly alleviated the mechanical hypersensitivity associated with SN-CCI (Fig. 6). Indeed, the withdrawal threshold value in the vehicleinjected SN-CCI group decreased during the $3 \mathrm{~d}$ of intrathecal treatment (days 15, 16, and 17 after surgery), whereas no such decreased was observed in the vehicle-administered sham-operated rats [thus, at postoperative day 17 (POD 17), withdrawal threshold values were $3.37 \pm 0.48 \mathrm{~g}$ in vehicle-injected SN-CCI rats vs $14.34 \pm 0.66 \mathrm{~g}$ $(p<0.001)$ in vehicle-injected sham rats]. In contrast, SN-CCI rats treated with the CCR2 antagonist had a significantly higher weight threshold than vehicle-injected SN-CCI rats, from the day of the second injection, at POD 16 (INCB3344-injected SN-CCI rats, $8.32 \pm 2.23$ g; vehicle-injected SN-CCI rats, $4.19 \pm 0.71 \mathrm{~g} ; p<0.05)$. The maximal effect of intrathecal INCB3344 administration on SN-CCIinduced mechanical allodynia was observed after the third injection at POD 17 (INCB3344-injected SN-CCI rats, $9.38 \pm 1.85$ g; vehicleinjected SN-CCI rats, $3.37 \pm 0.48 \mathrm{~g} ; p<0.01$ ).

\section{Discussion}

We demonstrated that CCL2 was present in the secretory vesicles of central terminals of primary afferent neurons, from which it may be released. Peripheral nerve injury (SN-CCI) increases the release of CCL2 in the DHSC, and this is associated with the prolonged upregulation of CCL2 mRNA levels in the ipsilateral DRG and DHSC. We further showed that the pronociceptive action of CCL2 was related to its ability to upregulate the expression of several proinflammatory genes and to induce neuronal and microglial ERK1/2 phosphorylation in the DHSC. These effects were abolished by CCR2 antagonist treatment. In the pathological pain conditions (SN-CCI), the CCR2 antagonist INCB3344 also abolished the increase in ERK1/2 signaling in spinal microglia, significantly decreased microglial activation and the abnormal ex- pression of several key proinflammatory/proalgesic markers, and attenuated established mechanical allodynia.

\section{CCL2 may act as neuromodulator in the DHSC}

We showed previously that CCL2 was present in primary afferent neurons and their processes in the DHSC, in which it was colocalized with classical peptides substance P (SP) and calcitonin gene-related peptide (CGRP), together with TRPV1 (Dansereau et al., 2008). However, although CCL2 expression in the DRG and DHSC neurons is well documented (for review, see Miller et al., 2009), little is known about its subcellular distribution. Our electron microscopy studies revealed that neuronal CCL2-IR was sorted to presynaptic SCV and DCV in glomerular boutons. Furthermore, CCL2-IR was detected along the microtubule network of unmyelinated and thinly myelinated axons, strongly suggesting that CCL2, like SP and CGRP, is transported from DRG neurons to central axon terminals. These classical neuropeptides are mostly stored in DCVs and released during depolarization in response to nociceptive stimuli, to exert their pronociceptive neuromodulatory action on postsynaptic neurons. Together with 


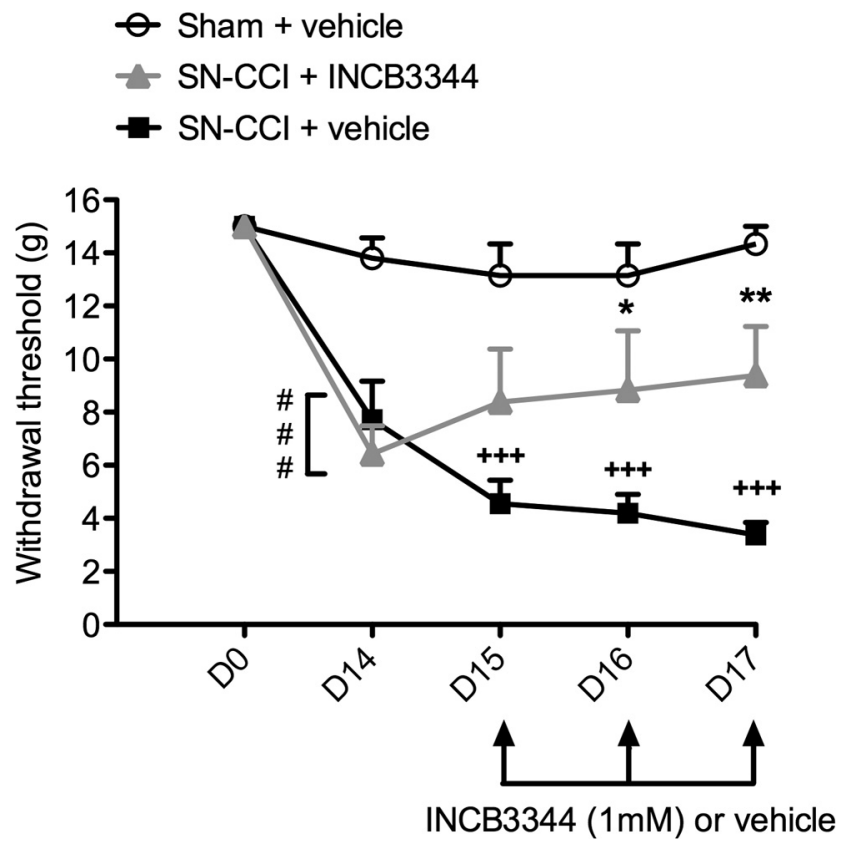

Figure 6. Effect of INCB3344 on mechanical allodynia in SN-CCl rats. Intrathecal injections of INCB3344 (1 mM) or vehicle were performed 15, 16, and $17 \mathrm{~d}$ after surgery. Mechanical allodynia was evaluated with the von Frey test 0 and $14 \mathrm{~d}$ after surgery and then 15,16 , and $17 \mathrm{~d}$ after surgery, $2 \mathrm{~h}$ after the injection on those days. Each point is the mean \pm SEM of $n=6-9$ animals per group. $t$ test: ${ }^{\# \#} p<0.001, \mathrm{SN}-\mathrm{CCl}$ rats versus sham-operated rats $14 \mathrm{~d}$ after surgery; two-way ANOVA followed by the Bonferroni's post hoc test was used: ${ }^{*} p<0.05$ and ${ }^{* *} p<$ $0.01, \mathrm{SN}-\mathrm{CCl}$ INCB3344-injected rats versus SN-CCl vehicle-injected rats; ${ }^{+++} p<0.001, \mathrm{SN}-$ $\mathrm{CCl}$ vehicle-injected rats versus sham-operated vehicle-injected rats.

our previous report showing that CCL2 is released during depolarization from DHSC and is found, at least partly, in the same subcellular fraction as SP (Dansereau et al., 2008), these data suggest that some CCL2 may be secreted from the same pool of neurons as SP and CGRP.

The major part of neuropeptide-containing neurons in the DRG are TRPV1 positive and can be selectively destroyed by neonatal treatment with capsaicin (Pohl et al., 1990). Here, this treatment decreased the depolarization-evoked CCL2 release from DHSC explants by $\sim 65 \%$. These results are in line with our immunohistochemical and ultrastructural data on CCL2-IR localization in rat DHSC and suggest that a major part of spinal CCL2 was released from DSVs of nociceptive TRPV1-containing peptidergic primary afferent fibers. However, after capsaicin treatment, a significant portion of CCL2 was still released from spinal explants after $\mathrm{K}^{+}$depolarization, very probably representing the CCL2 present in intrinsic spinal cord neurons-demonstrated in our previous work (Dansereau et al., 2008) - and the CCL2 pool localized in spinal terminals of capsaicin-insensitive primary neurons. The presence of CCL2-IR in SCVs is consistent with its continuous basal secretion from DHSC explants in both control and capsaicin-treated rats. CCL2 therefore resembles the neuropeptides detected in SCVs (Chan-Palay and Palay, 1977; Cuello et al., 1977; Ribeiro-da-Silva et al., 1989). This basal release, mobilizing preferentially SCVs, is a rather passive phenomenon independent of calcium (Dansereau et al., 2008). The characteristics of the basal CCL2 release from the rat DHSC thus closely resembles those of SP completely insensitive to the neonatal capsaicin treatment and the presence or not of $\mathrm{Ca}^{2+}$ (Pohl et al., 1989a).

We previously showed that CCL2 inhibits GABA-induced currents via the $\mathrm{GABA}_{\mathrm{A}}$ receptor in the DHSC (Gosselin et al., 2005).
This effect is instantaneous, occurring within milliseconds of CCL2 application, suggesting a direct effect of the chemokine on DHSC neurons via its own receptors and not through the release of other mediators (Gosselin et al., 2005). CCL2 was shown recently to potentiate spinal NMDA- and AMPA-receptor-associated ionic currents and to sensitize nociceptors by activating capsaicin receptors, two mechanisms known to participate in spinal sensitization (Jung et al., 2008; Gao et al., 2009). CCL2 may therefore be considered as another pronociceptive neuromodulator.

\section{CCL2 and DHSC neuroinflammation}

There is accumulating evidence to suggest that chemokines, including CCL2, may be involved in inflammation-related pain hypersensitivity (Johnston et al., 2004; Milligan et al., 2004, 2005). We showed previously that the intrathecal injection of CCL2 in naive rats induces mechanical and thermal hypersensitivity that can be prevented by coadministration of the CCR2 antagonist INCB3344 (Dansereau et al., 2008). However, the mechanisms underlying CCL2-evoked pain hypersensitivity remained essentially unknown. We show here that intrathecal injection of CCL2 induces rapid upregulation of proinflammatory mediators expression (IL6, IL1 $\beta$, COX2, and CCL2) in the DHSC. In addition, CCL2 also evoked the phosphorylation of ERK1/2 in DHSC neurons and microglia. This signaling pathway, activated in DHSC neurons after peripheral noxious stimulation or inflammation (Galan et al., 2002; Ji et al., 2002) and in various cell types during the development of neuropathic pain, was demonstrated previously to participate in pain hypersensitivity developing after peripheral nerve injury (Song et al., 2005; Zhuang et al., 2005). Interestingly, all these effects were blocked by INCB3344, suggesting that CCL2, via CCR2, induced an inflammatory pattern in the DHSC, activated ERK1/2 signaling and, ultimately, evoked pain hypersensitivity. Our demonstration that in animals pretreated with MEK1 inhibitor (PD98059) leading to the blockade of ERK1/2 pathway, CCL2 intrathecal administration fails to induce spinal accumulation of p-ERK1/2-IR and development of pain hypersensitivity, supports a relationship between CCL2 (acting through its CCR2 receptors), activation of ERK1/2 signaling, and emergence of pain.

Of particular interest is the observation that the intrathecal injection of CCL2 induced the synthesis of its own mRNA in the DHSC, an effect that was blocked by INCB3344. We did not identify the type of cell in which CCL2 expression was enhanced. Nevertheless, this observation suggests that CCL2 may induce its own synthesis after its initial release in the DHSC, possibly from neuronal stores, thereby amplifying its local impact on the production of inflammatory factors and the induction of spinal tissue plasticity.

The data presented here for the pathological conditions induced by SN-CCI confirm this hypothesis. Indeed, SN-CCI animals had higher levels of depolarization-evoked CCL2 release from the DHSC, suggesting higher levels of neuronal storage of this chemokine. SN-CCI also induced the long-term upregulation of CCL2 mRNA in the DRG and DHSC, consistent with previous reports of higher CCL2 protein levels (Jeon et al., 2009). These higher CCL2 mRNA levels in SN-CCI rats were completely abolished by intrathecal treatment with a CCR2 antagonist. Furthermore, inflammatory markers induced by exogenous CCL2 in normal rats were also upregulated in SN-CCI rats, and, more importantly, their abnormal expression was decreased by intrathecal INCB3344. Similarly, INCB3344 also partly decreased ITGAM mRNA levels and Iba1-IR in the DHSC of SN-CCI rats, 
suggesting that CCR2 blockade may decrease peripheral nerve injury-associated microglial activation $17 \mathrm{~d}$ after surgery.

INCB3344 also abolished the increase in p-ERK1/2-IR observed in the spinal microglia of SN-CCI rats. Several lines of evidence suggest that ERK1/2 pathway activation participates in neuropathic pain states and central sensitization. The ERK1/2 activity in spinal microglia triggered by peripheral nerve injury (Cheng et al., 2003; Zhuang et al., 2005; Tsuda et al., 2008) has been shown to be involved in COX2 and NOS2 expression (Bhat et al., 1998; Chun and Surh, 2004; Zhao et al., 2007). Thus, our observation that CCR2 antagonist completely blocks microglial ERK1/2 phosphorylation may partly account for the inhibitory effect of this antagonist on the production of NOS2, IL1 $\beta$, and COX2. Spinal cord long-term potentiation (LTP), a key process in spinal sensitization in neuropathic pain states, has been shown recently to be associated with an upregulation of essentially glial cell-expressed genes, such as NOS2 and IL1 $\beta$ (Pedersen et al., 2010). These data thus provide additional support for the notion that LTP involves both neurons and activated glial cells ( $\mathrm{Ma}$ and Zhao, 2002). Finally, prostaglandin E2 (PGE2), an important glia-neuron signaling molecule released by microglia, seems to act on specific neuron receptors and plays a prominent role in central sensitization (Samad et al., 2001; Ji et al., 2003). Thus, CCL2 may participate in the central sensitization of nociceptive neurons by controlling glial nitric oxide and PGE2 production.

Our data demonstrate that endogenous CCL2 acts as a key factor in both the initiation and maintenance of neuroinflammation in the spinal cord after peripheral nerve injury. Spinal neuroinflammation is closely linked to the development and maintenance of neuropathic pain (Myers et al., 2006). In this case, CCR2 blockade may alleviate mechanical allodynia, a prominent symptom associated with neuropathic pain. We demonstrated this effect here, by showing that the treatment of SN-CCI rats with INCB3344 attenuated established mechanical allodynia. This result extends the recent finding (Thacker et al., 2009) that the intrathecal injection of CCL2 antibody soon after peripheral nerve injury attenuates the development of mechanical hypersensitivity. In addition, the observation that CCR2 antagonists have a similar effect on pain hypersensitivity in other neuropathic pain models (Bhangoo et al., 2009) clearly supports the notion that CCR2 is a potentially interesting treatment target.

In conclusion, the ultrastructural, biochemical, and behavioral data presented here demonstrate that CCL2 is endowed with all the characteristics typical of a neuronal mediator involved in the induction and maintenance of neuropathic pain states and that CCR2 antagonists represent promising tools for treating this condition.

\section{References}

Abbadie C, Lindia JA, Cumiskey AM, Peterson LB, Mudgett JS, Bayne EK, DeMartino JA, MacIntyre DE, Forrest MJ (2003) Impaired neuropathic pain responses in mice lacking the chemokine receptor CCR2. Proc Natl Acad Sci U S A 100:7947-7952.

Bennett GJ, Xie YK (1988) A peripheral mononeuropathy in rat that produces disorders of pain sensation like those seen in man. Pain 33:87-107.

Bhangoo SK, Ripsch MS, Buchanan DJ, Miller RJ, White FA (2009) Increased chemokine signaling in a model of HIV1-associated peripheral neuropathy. Mol Pain 5:48.

Bhat NR, Zhang P, Lee JC, Hogan EL (1998) Extracellular signal-regulated kinase and p38 subgroups of mitogen-activated protein kinases regulate inducible nitric oxide synthase and tumor necrosis factor- $\alpha$ gene expression in endotoxin-stimulated primary glial cultures. J Neurosci 18: 1633-1641.

Brodmerkel CM, Huber R, Covington M, Diamond S, Hall L, Collins R, Leffet L, Gallagher K, Feldman P, Collier P, Stow M, Gu X, Baribaud F, Shin N,
Thomas B, Burn T, Hollis G, Yeleswaram S, Solomon K, Friedman S, Wang A, Xue CB, Newton RC, Scherle P, Vaddi K (2005) Discovery and pharmacological characterization of a novel rodent-active CCR2 antagonist, INCB3344. J Immunol 175:5370-5378.

Cesselin F, Bourgoin S, Artaud F, Hamon M (1984) Basic and regulatory mechanisms of in vitro release of Met-enkephalin from the dorsal zone of the rat spinal cord. J Neurochem 43:763-774.

Chan-Palay V, Palay SL (1977) Ultrastructural identification of substance P cells and their processes in rat sensory ganglia and their terminals in the spinal cord by immunocytochemistry. Proc Natl Acad Sci U S A 74:4050-4054.

Chaplan SR, Bach FW, Pogrel JW, Chung JM, Yaksh TL (1994) Quantitative assessment of tactile allodynia in the rat paw. J Neurosci Methods 53:55-63.

Cheng AW, Kong LW, Tung EK, Siow NL, Choi RC, Zhu SQ, Peng BH, Tsim KW (2003) cDNA encodes Xenopus P2Y(1) nucleotide receptor: expression at the neuromuscular junctions. Neuroreport 14:351-357.

Chun KS, Surh YJ (2004) Signal transduction pathways regulating cyclooxygenase-2 expression: potential molecular targets for chemoprevention. Biochem Pharmacol 68:1089-1100.

Coimbra A, Ribeiro-da-Silva A, Pignatelli D (1984) Effects of dorsal rhizotomy on the several types of primary afferent terminals in laminae I-III of the rat spinal cord. An electron microscope study. Anat Embryol (Berl) 170:279-287.

Cuello AC, Jessell TM, Kanazawa I, Iversen LL (1977) Substance P: localization in synaptic vesicles in rat central nervous system. J Neurochem 29:747-751.

Dansereau MA, Gosselin RD, Pohl M, Pommier B, Mechighel P, Mauborgne A, Rostene W, Kitabgi P, Beaudet N, Sarret P, Melik-Parsadaniantz S (2008) Spinal CCL2 pronociceptive action is no longer effective in CCR2 receptor antagonist-treated rats. J Neurochem 106:757-769.

Galan A, Lopez-Garcia JA, Cervero F, Laird JM (2002) Activation of spinal extracellular signaling-regulated kinase- 1 and -2 by intraplantar carrageenan in rodents. Neurosci Lett 322:37-40.

Gao YJ, Zhang L, Samad OA, Suter MR, Yasuhiko K, Xu ZZ, Park JY, Lind AL, Ma Q, Ji RR (2009) JNK-induced MCP-1 production in spinal cord astrocytes contributes to central sensitization and neuropathic pain. J Neurosci 29:4096-4108.

Gosselin RD, Varela C, Banisadr G, Mechighel P, Rostene W, Kitabgi P, Melik-Parsadaniantz S (2005) Constitutive expression of CCR2 chemokine receptor and inhibition by MCP-1/CCL2 of GABA-induced currents in spinal cord neurones. J Neurochem 95:1023-1034.

Gosselin RD, Dansereau MA, Pohl M, Kitabgi P, Beaudet N, Sarret P, Mélik Parsadaniantz S (2008) Chemokine network in the nervous system: a new target for pain relief. Curr Med Chem 15:2866-2875.

Jeon SM, Lee KM, Cho HJ (2009) Expression of monocyte chemoattractant protein-1 in rat dorsal root ganglia and spinal cord in experimental models of neuropathic pain. Brain Res 1251:103-111.

Ji RR, Befort K, Brenner GJ, Woolf CJ (2002) ERK MAP kinase activation in superficial spinal cord neurons induces prodynorphin and NK-1 upregulation and contributes to persistent inflammatory pain hypersensitivity. J Neurosci 22:478-485.

Ji RR, Kohno T, Moore KA, Woolf CJ (2003) Central sensitization and LTP: do pain and memory share similar mechanisms? Trends Neurosci 26:696-705.

Johnston IN, Milligan ED, Wieseler-Frank J, Frank MG, Zapata V, Campisi J, Langer S, Martin D, Green P, Fleshner M, Leinwand L, Maier SF, Watkins LR (2004) A role for proinflammatory cytokines and fractalkine in analgesia, tolerance, and subsequent pain facilitation induced by chronic intrathecal morphine. J Neurosci 24:7353-7365.

Jung H, Toth PT, White FA, Miller RJ (2008) Monocyte chemoattractant protein-1 functions as a neuromodulator in dorsal root ganglia neurons. J Neurochem 104:254-263.

Ma JY, Zhao ZQ (2002) The involvement of glia in long-term plasticity in the spinal dorsal horn of the rat. Neuroreport 13:1781-1784.

Mauborgne A, Lutz O, Legrand JC, Hamon M, Cesselin F (1987) Opposite effects of delta and mu opioid receptor agonists on the in vitro release of substance P-like material from the rat spinal cord. J Neurochem 48 : 529-537.

Maxwell DJ, Christie WM, Short AD, Storm-Mathisen J, Ottersen OP (1990) Central boutons of glomeruli in the spinal cord of the cat are enriched with L-glutamate-like immunoreactivity. Neuroscience 36:83-104. 
Miller RJ, Jung H, Bhangoo SK, White FA (2009) Cytokine and chemokine regulation of sensory neuron function. Handb Exp Pharmacol 194:417-449.

Milligan ED, Watkins LR (2009) Pathological and protective roles of glia in chronic pain. Nat Rev Neurosci 10:23-36.

Milligan ED, Zapata V, Chacur M, Schoeniger D, Biedenkapp J, O'Connor KA, Verge GM, Chapman G, Green P, Foster AC, Naeve GS, Maier SF, Watkins LR (2004) Evidence that exogenous and endogenous fractalkine can induce spinal nociceptive facilitation in rats. Eur J Neurosci 20:2294-2302.

Milligan E, Zapata V, Schoeniger D, Chacur M, Green P, Poole S, Martin D, Maier SF, Watkins LR (2005) An initial investigation of spinal mechanisms underlying pain enhancement induced by fractalkine, a neuronally released chemokine. Eur J Neurosci 22:2775-2782.

Myers RR, Campana WM, Shubayev VI (2006) The role of neuroinflammation in neuropathic pain: mechanisms and therapeutic targets. Drug Discov Today 11:8-20.

Pedersen LM, Jacobsen LM, Mollerup S, Gjerstad J (2010) Spinal cord longterm potentiation (LTP) is associated with increased dorsal horn gene expression of IL-1beta, GDNF and iNOS. Eur J Pain 14:255-260.

Pohl M, Mauborgne A, Bourgoin S, Benoliel JJ, Hamon M, Cesselin F (1989a) Neonatal capsaicin treatment abolishes the modulations by opioids of substance P release from rat spinal cord slices. Neurosci Lett 96:102-107.

Pohl M, Lombard MC, Bourgoin S, Carayon A, Benoliel JJ, Mauborgne A, Besson JM, Hamon M, Cesselin F (1989b) Opioid control of the in vitro release of calcitonin gene-related peptide from primary afferent fibres projecting in the rat cervical cord. Neuropeptides 14:151-159.

Pohl M, Benoliel JJ, Bourgoin S, Lombard MC, Mauborgne A, Taquet H, Carayon A, Besson JM, Cesselin F, Hamon M (1990) Regional distribution of calcitonin gene-related peptide-, substance P-, cholecystokinin-, Met5-enkephalin-, and dynorphin A (1-8)-like materials in the spinal cord and dorsal root ganglia of adult rats: effects of dorsal rhizotomy and neonatal capsaicin. J Neurochem 55:1122-1130.

Ribeiro-da-Silva A, Coimbra A (1982) Two types of synaptic glomeruli and their distribution in laminae I-III of the rat spinal cord. J Comp Neurol 209:176-186.

Ribeiro-da-Silva A, Tagari P, Cuello AC (1989) Morphological characterization of substance P-like immunoreactive glomeruli in the superficial dorsal horn of the rat spinal cord and trigeminal subnucleus caudalis: a quantitative study. J Comp Neurol 281:497-515.
Samad TA, Moore KA, Sapirstein A, Billet S, Allchorne A, Poole S, Bonventre JV, Woolf CJ (2001) Interleukin-1beta-mediated induction of Cox-2 in the CNS contributes to inflammatory pain hypersensitivity. Nature 410:471-475.

Scholz J, Woolf CJ (2007) The neuropathic pain triad: neurons, immune cells and glia. Nat Neurosci 10:1361-1368.

Song XS, Cao JL, Xu YB, He JH, Zhang LC, Zeng YM (2005) Activation of ERK/CREB pathway in spinal cord contributes to chronic constrictive injury-induced neuropathic pain in rats. Acta Pharmacol Sin 26:789-798.

Tanaka T, Minami M, Nakagawa T, Satoh M (2004) Enhanced production of monocyte chemoattractant protein-1 in the dorsal root ganglia in a rat model of neuropathic pain: possible involvement in the development of neuropathic pain. Neurosci Res 48:463-469.

Thacker MA, Clark AK, Bishop T, Grist J, Yip PK, Moon LD, Thompson SW, Marchand F, McMahon SB (2009) CCL2 is a key mediator of microglia activation in neuropathic pain states. Eur J Pain 13:263-272.

Tsuda M, Ueno H, Kataoka A, Tozaki-Saitoh H, Inoue K (2008) Activation of dorsal horn microglia contributes to diabetes-induced tactile allodynia via extracellular signal-regulated protein kinase signaling. Glia 56: 378-386.

White FA, Miller RJ (2010) Insights into the regulation of chemokine receptors by molecular signaling pathways: functional roles in neuropathic pain. Brain Behav Immun 24:859-865.

White FA, Sun J, Waters SM, Ma C, Ren D, Ripsch M, Steflik J, Cortright DN, Lamotte RH, Miller RJ (2005) Excitatory monocyte chemoattractant protein- 1 signaling is up-regulated in sensory neurons after chronic compression of the dorsal root ganglion. Proc Natl Acad Sci U S A 102: 14092-14097.

White FA, Jung H, Miller RJ (2007) Chemokines and the pathophysiology of neuropathic pain. Proc Natl Acad Sci U S A 104:20151-20158.

Zhao P, Waxman SG, Hains BC (2007) Modulation of thalamic nociceptive processing after spinal cord injury through remote activation of thalamic microglia by cysteine cysteine chemokine ligand 21. J Neurosci 27: 8893-8902.

Zhuang ZY, Gerner P, Woolf CJ, Ji RR (2005) ERK is sequentially activated in neurons, microglia, and astrocytes by spinal nerve ligation and contributes to mechanical allodynia in this neuropathic pain model. Pain 114: $149-159$. 